\title{
Video Assisted Teaching Module (VATM): developed for primary caregivers on home care of schizophrenic patient
}

\begin{abstract}
Schizophrenia is a chronic mental disorder and caregivers' role plays vital in all aspects of concern. When they gain knowledge, positive attitude and skill in taking care, can prevent the relapse of the patient and prevent distress of the caregivers. Innovative educational programs can make a valuable contribution. Videotapes can be effective teaching tools for patients and caregivers by facilitating knowledge acquisition, reducing anxiety, improving coping skills, and enhancing self care behaviors. They are valuable resources for assistance in educating patients and caregivers in today's changing health care environment. They incorporate visual and auditory information into a teaching modality that is often easy for individuals to understand and retain. This paper attempts to explain the development process of VATM. The development of a new and promising resource (VATM) for primary caregivers on home care of schizophrenic patients is detailed in this article. This paper is based on the author's own experience of producing VATM. Pertinent literature was reviewed and the video assisted teaching module was developed. The production of VATM is broadly categorized into pre production, production and post production. Each and every step of this VATM is clearly explained in this paper. It is hoped that this paper will be helpful to prospective Medical, Nursing and also for educators in various fields intending to produce similar VATM. Video is more popular, it has unique features that capture accurately and comprehensively the nature of nursing phenomena and provides continuous multi-media, multi-sensory information about the subject and its context.
\end{abstract}

Keywords: video assisted teaching module, vatm, homecare,schizophrenia, caregiver
Volume 5 Issue 6 - 2018

\author{
Balasubramanian N,' Asha P Shetty, \\ Sathyanarayana Rao TS $^{3}$ \\ 'Ambika college of Nursing, India \\ ${ }^{2}$ Yenepoya Nursing College, India \\ ${ }^{3}$ Department of Psychiatry, JSS University, India
}

\author{
Correspondence: Balasubramanian N, Principal,Ambika \\ college of Nursing, Mohali, Punjab, India, \\ Emailsmbalu78@gmail.com
}

Received: May 03, 2017 | Published: November 19, 2018

\section{Introduction}

The vital role ofHealth Promotion is a research based communication process involving planning, design, and implementation of strategic intervention. It provides relevant information and adequate motivation to impact attitudes and behaviors in individuals or groups. ${ }^{1}$ Health education has always been a vital component of nursing. ${ }^{2}$ Nurses have a long history as patient educators. Patient teaching is a tenet of all nursing education programs and an important nursing role. ${ }^{3,4}$ Most nurses recognize the importance of patient and caregiver education but are frustrated by the lack of time and resources to support it. They know that the limited time they have with patients can restore health to some degree, but the patient and family are ultimately responsible for continuing the gains and maintaining health through self-care. ${ }^{5}$ Nurses often respond to the pressure by saying they have "no time to teach" and then ask, "How can I get more time to teach?" In these tight economic times, the response is a frustrating "no money, no staff, no time." As our world changes, the methods available to teach patients and caregivers expand. Using video as a method of teaching has been found to be an effective and economic in times of nursing shortage. ${ }^{6}$ The use of educational video offers many favorable characteristics in the variety field of medical and nursing area. Video teaching can provide a consistent from of teaching and can communicate certain concepts in a visual and realistic manner. ${ }^{7}$ Furthermore, video education has been shown to be superior to traditional method and improve knowledge score. ${ }^{8,9}$ The purpose of this study was to evaluate how the implementation of a VATM on home care of schizophrenic patient would influence the caregiver understanding of the nature of illness, attitude towards the patient, treatment and social interaction, caregiver's burden and skill in handling schizophrenic patient at home.

\section{Video assisted teaching module}

Video is the technology of electronically capturing, recording, processing, storing, transmitting, and reconstructing a sequence of still images representing scenes in motion. ${ }^{10}$ Video improves learning because it uses sight, sound and motion to present simple illustrations of complex medical topics and issues, can present information in a manner that verbal descriptions, or talking alone, simply cannot convey and act as a bridge educational barriers, i.e. patients with low reading skills can learn more easily from video. It helps to overcome language barriers because illustrations and pictorial-based procedures communicate without words. It is a tool that helps nurses and patient educators enhance their patient interactions during follow up discussions by providing a point of reference or common ground for discussion. Furthermore it can convey the information concisely and consistently, while in other methods may accidentally omit something during multiple, repetitive discussions, the video never varies and also helps the educator illustrate or model proper patient behavior as well as show what to do rather than what not to do. It is very beneficial for family caregivers because it provides them with valuable information and helps reduce the anxiety and fear they may feel when thinking about how they will administer in-home care after discharge. ${ }^{11-15}$ Video helps patients understand and better prepare themselves as they face life changing diseases such as Diabetes, Alzheimer's, and other chronic illnesses. Video can help patients and families with end of life decisions as patients with a chronic disease will face important decisions regarding their on-going care. ${ }^{16}$ Further, it is used to monitor performance assessment feedback, instructional assessment feedback and situational assessment feedback. ${ }^{17}$ In this VATM study all the three types of feedback have been obtained. 


\section{Video assisted teaching module for caregivers of schizophrenic patients}

An estimated 24 million (1\%) people worldwide suffer from schizophrenia. ${ }^{18}$ It is a severe disorder that characterized distortions in thinking and perception and by inappropriate emotions. It follows a chronic or recurrent course with residual symptoms and incomplete social recovery. ${ }^{19}$ Schizophrenia not only influences the lives of those affected but also those around them especially caregivers. ${ }^{20}$ Interestingly, one of the most important innovations occurred in a mental hospital setting is that the active involvement of families in the care of mentally ill persons which helps in relapse. ${ }^{21}$ Hence, investigator selected family primary caregivers as subjects for this study. The objectives of this VATM on Homecare of schizophrenic patient among primary caregivers is to understand the nature of illness, to improve positive attitude towards the patient, to develop skill in taking care of patients at home, to decrease the burden through effective coping and adjustment.

\section{The issues to be considered before beginning} the video

Video is ideal for presenting human behaviors. There are two quite different subclasses of "doing outcomes" those involving attitude and those involving skills. For attitudes, people readily learn by modeling other people's behaviors .People can model other people so well that learning can be unintentional. ${ }^{22}$ Before preparing educational video, think about its "shelf life". It means that the video will be relevant one or two years from at the present. Think of educational video preparation because it takes a time and effort, the video should be useful when it's released, if the video become outdated when it released, the video will become outdated. Consider how long it will take to produce the video because the video production indeed a lengthy process. ${ }^{23}$ Video is a tool like a handout or brochure but it provides a different learning environment and important for the nurse to work with the patient before and after the video to set the stage for attentive viewing and active learning and it is cost effective approach. ${ }^{24}$ Provide pen and paper and encourage them to take notes and give everyone a few moments to jot down ideas and questions they may have about the information in the documentary. ${ }^{25}$

\section{Steps involved in video teaching module on home care of schizophrenic patient}

There are three main phases associated with video production i.e., pre-production, production and post production (Table 1) ${ }^{26}$

Table I The schematic representation of video production

\begin{tabular}{|c|c|c|c|c|}
\hline \multicolumn{2}{|c|}{ Phase-I } & \multicolumn{2}{|c|}{ Phase-II } & Phase-III \\
\hline \multicolumn{2}{|c|}{ Pre production } & \multicolumn{2}{|c|}{ Production } & Post production \\
\hline$\bullet$ & $\begin{array}{l}\text { Review of relevant } \\
\text { literature }\end{array}$ & & Shooting & - $\quad$ Editing \\
\hline$\bullet$ & Script writing & i. & $\begin{array}{l}\text { Arranging the } \\
\text { set }\end{array}$ & - Illuminative evaluation \\
\hline i. & Script mapping & ii. & $\begin{array}{l}\text { Organizing } \\
\text { lighting }\end{array}$ & $\begin{array}{l}\text { - Development of criteria check list to validate video assisted } \\
\text { teaching module }\end{array}$ \\
\hline ii. & $\begin{array}{l}\text { Planning and prepa- } \\
\text { ration }\end{array}$ & iii. & Camera angles & - Content validity of the video assisted teaching module \\
\hline iii. & Formatting & iv. & $\begin{array}{l}\text { Position of the } \\
\text { actors }\end{array}$ & - Reliability through validated criteria check list \\
\hline iv. & Drafting & & & - $\quad$ Pretesting \\
\hline v. & Writing & & & \\
\hline
\end{tabular}

The steps involved are as follows:

Pre-production: Pre production involves following steps.

i. Literature review: Before beginning the video assisted teaching module look at existing literature in an area of interest. Literature review gives a critical summary of the topic of interest. ${ }^{27}$ In relation to writing the script, careful attention was required to ensure that the content was accurate and also up to date. The source of the information accessed in writing the script included books, journals, articles, published and unpublished theses related to schizophrenia and its homecare was reviewed to have an idea to develop video assisted teaching module.

ii. Script Writing: Nothing happens without a good script. There is a nuance to this task. Good videos require a certain expertise. A script is not like writing an article or a book. Remember, a script will be heard and not read. If the video is not scripted (as in a testimonial or "talking head" videos), consider a rough script (as in what you want the interviewee to say) prior to the shooting. Writing for video is a challenging endeavor and a complex subject. The script is not only the written form of the program content; it is also an item that provides integrity between visual and auditory elements. Language is the basic exposition method and that there are two different exposition languages, namely, "visual" and "auditory". It is very important to use the most adaptable exposition language with the selected technologies..$^{28}$ The first step of any video production is writing an exact and detailed script. This was particularly important for videos demonstrating best practice in fundamental healthcare techniques. The script writing took many rounds of drafting, circulation, feedback and revision. ${ }^{29}$ Video script is a kind of map, a blueprint of what is going to be in the video module. It is something akin to the architect's plan. The video script was prepared by keeping in mind with the study background, objectives, feasibility and practicability and also clear, concise and to avoid non technical language. ${ }^{29}$ The case scenario was 
developed based on the content and ideas are created through brainstorming. When writing scenes description of each scene in script include environment (settings), background music, and animations include notes about which actors appear in each scene dialogue for actors, read over dialogue was written to be sure that it is logical, clear, and understandable.

\section{Process of script writing}

i. Script mapping: Prepare the script mapping, which is a map for assemble the video production. The script mapping is the structure of the project, to assist the voice-over reader when recording, and enable to imagine how the finished project will look

ii. Research the story: Caregivers of schizophrenic patient were interviewed regarding Homecare and associated issues are identified. To create the story line which investigator wants to communicate to them. Make a note of their knowledge, attitude, burden, and practice of care while communicating with them through open ended questions. Observe and make a note in which area they lack information, what is the cause of their burden, what is their attitude towards schizophrenia and how they were taking care of patients at home.

iii. Formatting: Be familiar with scripting formats. One useful format is to divide the page in two, with visual information and its location on the raw camera tape (visual) on the right hand side, and audio and text based material on the left. ${ }^{30}$ The same format is modified and divided the page into 5 columns i.e., S.No, content, audio, visual and remarks. In the serial number column, continuous number of each and every scene is given, to be sure with educational contents the content is kept aside. In the audio column, the shots with the dialogues of the characters were written. The dialogues are written in direct speech and in simple language. The name of the characters was written in capital letter. The medical and nursing terminologies also explained in simple native language. The special effects such as animations, slides are mentioned in the visual column. In the remarks column some pictures or animations to be included in the video is mentioned.

iv. Writing and drafting: Before videotaping a draft script based on the general areas to be covered was made. This acts as a map for the final script and helps to guide the project. It is usually takes a long time, the first draft goes smoothly and it was prepared after the groundwork is laid. The second draft was made after fine tuning of the first draft. Till guide and co-guide approval the draft was reconstructed. The final draft is the blueprint for the entire project.

The VATM on home care of schizophrenic patient was organized into 2 sections. Section I includes the meaning of schizophrenia, causes of schizophrenia, signs and symptoms of schizophrenia, types of schizophrenia, and the effects of schizophrenia. Section II dealt with the attitude of the caregivers towards the patient, treatment and social interaction and home care of the schizophrenic patient among primary caregivers. Home care includes personal hygiene, nutrition, social interaction, safety measures, medication and management of hallucination and delusion.

\section{Production}

Shooting: The shooting stage is what most people consider the production phase of a video. The investigator analyzed script before shooting with video program experts and locations, situations was also analyzed and suitable arrangements were made. The shooting was done with all resources i.e., the man (actors), matter, material, methods and visual aids. Talking head, Spontaneous interview, Staged interview, Documentary, Voice-over narration, Demonstration, Dramatization are the techniques used to make the video likely.

\section{Post production}

i. Editing: Video editing is the process of manipulating and rearranging video shots to create a new work. The Goals of Editing is to remove unwanted footage, Choose the best footage, Create a flow Add effects, graphics, music, etc, Alter the style, pace or mood of the video, Give the video a particular angle. ${ }^{31}$ Editing takes the most time of any step. It will take weeks longer than you think. Make a super rough cut, then a rough cut, then work from there. Cut it, watch it, take notes, and continue this process until you are satisfied. Let a trusted friend watch your rough cut. New eyes are always a good thing. Titles, music, sound editing, color correction and effects should be added only after you have a rough cut. Prepared module was edited by video expert. The investigator made a thorough review of the entire script through editing. The investigator paid great attention to pinpoint and rectify the errors not affecting the video program.

\section{ii. The final draft of the VATM consisted of two sections.}

Section I included the meaning of schizophrenia, causes of schizophrenia, signs and symptoms of schizophrenia.

Section II dealt with myths and facts on schizophrenia and home care management of schizophrenia.

iii. Illuminative evaluation: Illuminative evaluation is a form of evaluation in which information is sought via open-ended observation and questioning, rather than being measured against predetermined outcomes..$^{32}$ Thus, psychiatrist, psychiatric nurses were called to evaluate the video. Their critique, suggestion and opinion were made after consulting with guide and co-guide.

iv. Development of the criteria checklist for content validity: A list of criteria was prepared to assess the validity of the VATM, that is, to find out the relevancy of the content according expert's suggestions. Criteria checklist was developed by reviewing the existing related scales. ${ }^{33-36}$ and review of literature. The criteria checklist was developed and given to the subject experts $(n=5)$ who have doctorate degrees in mass communication $(n=2)$ and a doctorate degree in nursing as well as experienced and experts in developing video module $(n=3)$. After their suggestion content validity ratio and item analysis of the content validity was assessed. The content validity ratio was calculated through Lawshe formula $\left(C V R=\left(\mathrm{N}_{\mathrm{e}}-\mathrm{N} / 2\right) / \mathrm{N} / 2\right)$, based on their agree and disagree. The items in which experts disagree has a score of 0.2 , hence, the particular items are modified, whereas the items which scored 0 is the items agreed by all the experts, thus there is no modification in the items.

v. Content validity of the Video Assisted Teaching Module: Content validity refers to the extent to which a measure includes all of the dimensions of the phenomenon to be measured but does not include any extraneous dimensions. ${ }^{37}$ The final draft of Video Assisted Teaching Module was given to the 7 experts along with the criteria checklist. The experts were requested to validate the 
Video Assisted Teaching Module based on criteria checklist and to give suggestions on the adequacy and relevance of content.

vi. Reliability through criteria checklist:Reliability refers to the degree of consistency or accuracy with which an instrument measures the attribute it has been designed to measure. ${ }^{38}$ The VATM was shown to the primary caregivers to check the appropriateness, wording, information related to the topic. The content was analyzed before implementing the video. The VATM was shown to 10 primary caregivers of schizophrenic patient and asked them to validate the VATM in the criteria checklist. The tool was tool was divided into two equivalent halves and correlation for it was calculated using Karl Pearson formula and the significance of correlation was tested using the Spearman Brown Prophecy Formula. The ' $r$ ' value was 0.82 and the tool was found reliable (Annexure).

Annexure I Criteria checklist for content validity of video assisted teaching module on home care of schizophrenic patient

Kindly go through the video and please rate the video according to the following quality by putting a tick mark $(\sqrt{ })$ against the given column

\begin{tabular}{|c|c|c|c|c|c|c|}
\hline S.no & Items & $\begin{array}{l}\text { Strongly } \\
\text { agree }\end{array}$ & Agree & Neutral & Disagree & $\begin{array}{l}\text { Strongly } \\
\text { disagree }\end{array}$ \\
\hline 1 & Content aspects & & & & & \\
\hline \multirow{4}{*}{ I } & $\begin{array}{l}\text { The content of the video is: } \\
\text { I.I accurate and up to date }\end{array}$ & & & & & \\
\hline & 1.2 logically organized & & & & & \\
\hline & 1.3 in depth & & & & & \\
\hline & I.4 simple and clear & & & & & \\
\hline II & Presentation aspects & & & & & \\
\hline 2 & The video begins with a motivating and interesting manner. & & & & & \\
\hline 3 & $\begin{array}{l}\text { The procedures in the video are presented in a simplified } \\
\text { manner }\end{array}$ & & & & & \\
\hline 4 & The video periodically summarizes important content & & & & & \\
\hline 5 & $\begin{array}{l}\text { The procedures in the video are accurate in terms of } \\
\text { principles followed }\end{array}$ & & & & & \\
\hline 6 & The audio visuals are appropriate and correct & & & & & \\
\hline 7 & The languages used is clear and simple & & & & & \\
\hline 8 & The video meets the objectives and needs of the learner & & & & & \\
\hline III & Technical aspects & & & & & \\
\hline 9 & The video is well planned and organized & & & & & \\
\hline 10 & The video includes section breaks and section titles & & & & & \\
\hline 11 & The video has acceptable technical quality & & & & & \\
\hline 12 & $\begin{array}{l}\text { The video is such that it can be played on the available } \\
\text { equipment }\end{array}$ & & & & & \\
\hline 13 & The length and pace of the video is appropriate & & & & & \\
\hline
\end{tabular}

\section{Conclusion}

Video technology is becoming more popular because it has unique features that capture accurately and comprehensively the nature of nursing phenomena. Video technology is used extensively in nursing as an educational tool or intervention, a means of monitoring quality assurance standards. Videotaping is useful because it provides continuous multi-media, multisensory information about the subject and its context. Credibility of video data is based on the question of to what extent the data or results adequately represent true behavior.

\section{Acknowledgement}

The authors express sincere thanks to all the actors who acted in the VATM. The authors also extend gratitude to production people of
Mangalore and Bangalore for providing input during the development of this VATM.

\section{Conflicts of interest}

Author declares that there is none of the conflicts.

\section{References}

1. Suresh K. Evidence based communication for health promotion: Indian lessons of the last decades. Indian journal of public health. 2011;55(4):276-285.

2. Saarmann L, Daugherty J, Riegel B. Patient teaching to promote behavioral change. Nurse Outlook. 2000;48(6):281-287.

3. Piper SM, Brown PA. Theory and practice of health education applied to 
nursing: a bi-polar approach. J Adv Nurs. 1998;27(2):383-389.

4. Rifas E, Morris R, Grady R. Innovative approach to patient education. Nurs outlook. 1994;42:214-216.

5. Freda MC, Abruzzo M, Davini D, et al. Are they watching? Are they learning? Prenatal video education in the waiting room. J Perinat Ed. 1994;3:20-28.

6. Freda MC. Issues in Patient Education. $J$ Midwifery Womens Health. 2004;49(3):203-209.

7. Meade CD. Producing videotapes for cancer education: methods and examples. Oncol Nurs Forum. 1996;23(5):837-846.

8. Gagliano ME. A literature review on the efficacy of video in patient education. J MED Educ. 1988;63(10):785-792.

9. Phelan EA, Deyo RA, Cherkin DC, et al. Helping patients decide about back surgery: a randomized trial of an interactive video program. Spine (Phila Pa 1976). 2001;26(2):206-221.

10. Kaur H, Syal N. High motion video deblurring using probalistietic multiiteration method. International Journal of Engineering Research and Technology. 2012;1(6):1-5

11. Oermann MH, Webb SA, Ashare JA. Outcomes of videotape instruction in clinic waiting area. Orthopedic nursing. 2003;22(2):102-105.

12. Brooks BA, Using the internet for patient education. Orthopedic nursing 2001;20(5):69-77.

13. Krouse HJ. Video modeling to educate patients. Journal of advanced nursing. 2001;33(6):748-57.

14. Maller CE, Twitty VJ, Sauve A. A video approach to interactive patien education. Journal of peri anaesthesia nursing. 1997;12(2)82-88.

15. Meymandi A, Deaver EI. A new paradigm in patient education: A four part model using video tape production. Journal of psychiatric and mental health nursing. 1999;6(3):181-185.

16. Cjones. Video applications, synergy broadcast's blog on video in education, health care and cable. 2010.

17. Rosenstein B, Sheva B. Video use in social science research and program evaluation. International journal of qualitative methods. 2002;1(3):22-43.

18. Schizophrenia. World Health Organization. 2011.

19. Mental Health: New Understanding, New Hope. World Health Report. 2001.

20. Srinivasamurthy R. Mental health initiatives in India. The national medical journal of India. 2011;24(2):98-107.
21. Talwar P, Matheiken ST. Caregivers in schizophrenia: A cross cultural perspective. Indian Journal of Psychological Medicine. 2010;32:1:29-33.

22. Schwartz DL, Hartman K. It is not television anymore: Designing digital video for learning and assessment. Video research in the learning sciences. 2007. 25 p.

23. Telg R. Producing an educational video. University of Florida IFAS extension. 2012.

24. Fedyshin MK, Lawrence B. Collaborating to enhance patient education and recovery. J Med Libr Assoc.2005;93(4):440-445.

25. Safe Teen New Mexico and Christopher Productions. 2010. 19 p.

26. Corbally MA. Considering video production? Lessons learned from the production of a blood pressure measurement video. Nurse Education in practice. 2005;5(6):375-379.

27. Cronin P, Ryan F, Coughlan M. Undertaking literature review: step by step approach. British Journal of Nursing. 2008;17(10):38-43.

28. Ozgur AZ, Kaya S, Script writing process for multimedia materials in anadolu university open education faculty. 2007.

29. Cannon G, Kelly M, Lyng C, et al. The production and deployment of an online video learning bank in a skills training environment. AISHE-J. 2009;1(1):3-10.

30. Williams NH, Wolgin F, Hodge CS. Creating an educational videotape. Journal for Nurses in Staff development. 1998; 14(6):261-65.

31. Video editing.

32. Holliman R. Defining evaluation terminology. Isotope informing science outreach \& public engagement. 2009.

33. Beaudin BP, Quick D. Instructional Video evaluation instrument. Journal of extension. 1996;34(3).

34. Evaluation tool for suicide prevention video programs. American Association of Suicidology.

35. Video evaluation form. 2013.

36. Instructional Video Evaluation Form.

37. Tappen RM. Advanced Nursing Research: Theory to Practice. Jones \& Barlett Learning. 2011;140.

38. Polit D, Hungler B. Essentials of nursing research: methods, appraisal and utilization. 7th ed. USA: JB Lippincott Company; 2010. 